\title{
Modeling Learners' Readiness to Adopt Mobile Learning: A Perspective from a GCC Higher Education Institution
}

\author{
Mohammad Shorfuzzaman ${ }^{1}$ and Musaed Alhussein ${ }^{2}$ \\ ${ }^{1}$ Department of Computer Science, College of Computers and Information Technology, Taif University, Taif 21974, Saudi Arabia \\ ${ }^{2}$ Department of Computer Engineering, College of Computer \& Information Sciences, King Saud University, Riyadh 11451, Saudi Arabia
}

Correspondence should be addressed to Mohammad Shorfuzzaman; m.shorf@tu.edu.sa

Received 21 December 2015; Accepted 29 March 2016

Academic Editor: Miltiadis D. Lytras

Copyright (c) 2016 M. Shorfuzzaman and M. Alhussein. This is an open access article distributed under the Creative Commons Attribution License, which permits unrestricted use, distribution, and reproduction in any medium, provided the original work is properly cited.

\begin{abstract}
Mobile learning (M-learning) has gained significant popularity in recent past due to the explosion of portable devices and the availability of the Internet. The use of this specific technology in learning and training has enriched the success stories of next generation mobile information systems. While M-learning is being widely used in developed countries such as the USA, South Korea, Japan, UK, Singapore, Taiwan, and European Union, most of the Gulf Cooperation Council (GCC) countries are lagging behind and facing diversified challenges in adopting M-learning. Thus, investigating learners' readiness to adopt M-learning in higher education institution in the context of GCC is the focus of this paper. To this end, we introduce a hypothesized model to investigate learners' readiness to adopt M-learning. The empirical study is conducted by analyzing data collected from participants from a GCC university using a survey questionnaire with the help of statistical tools. The results of the study will be valuable for policy-makers in designing comprehensive M-learning systems in the context of GCC. The implication of the study results on the next generation mobile information system is also discussed with future research directions.
\end{abstract}

\section{Introduction}

Teaching and learning methods got new shape with the fast growth of Information and Communication Technology (ICT) and have become more efficient and productive. It is interesting to know that the initial advancement of education took place in the 20th century with prerecorded educational program being broadcasted through radio and television [1]. Learning through digital tools and electronic media, also called e-learning, turned out to be popular in the mid 90s with the advent of WWW [2]. Lately, the proliferation of portable devices ranging from mobiles phones to laptop computers and the emergence of new mobile technologies motivated educators and researchers to consider using them as a new medium of learning. For example, according to a Statista report, mobile phone user penetration rate all over the world was about $56.5 \%$ in 2013 and is expected to cross $65.34 \%$ by 2017 [3]. In KSA, according to a report for the Telecom and Information Technology sector released by the Communication and Information Technology Commission
[4], the overall count of cellular phone users reached around 53.1 million by the second quarter of 2015 , with a penetration rate of $170.5 \%$. Furthermore, the number of Internet users in the Kingdom is rising rapidly with a population penetration of $66 \%$ by the same time of the year. Figure 1 shows the ICT indicators in KSA by the second quarter of 2015 .

Thus, learning is no more restricted to classroom settings and conducted by the instructors only. Rather, it has reached a horizon which involves the application of portable devices as well as wireless technologies and allows the learners to learn anywhere and anytime [5]. In recent past, Mlearning has gained significant attention in designing mobile information systems and providing industry training in addition to general learning. The $\mathrm{M}$-learning clients range from laptop computers to mobile devices that have heterogenuos capabilities [6] with regard to resources such as computation power, display, and memory capacities for ubiquitous media learning content access [7]. Thus, learning contents need to be transcoded [8-11] to be properly viewed by the target learners and instructors or replicated [12] to be accessed from 


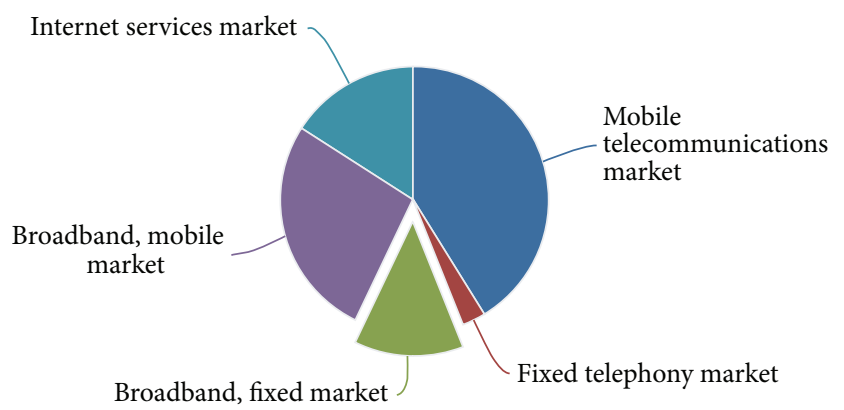

FIgURE 1: ICT indicators in KSA by the second quarter of 2015.

anywhere at any time from any devices to avoid learning content mismatch.

The rising interest in the field has motivated researchers all over the world to study M-learning phenomenon from the perspective of a unified learning strategy [13]. Educationally developed countries are coming up with policies to meet the ever growing demand of learning. They are discovering learning strategies by making the best utilization of portable devices and technologies. Mobile Learning Network (MoLeNET) in UK has funded 104 projects with a budget of $£ 12 \mathrm{~m}$ which involve approximately 40,000 learners and over 7,000 staff members. MoLeNET aims to provide a collaborative approach to introducing and supporting $\mathrm{M}$ learning in education and training [14]. According to the latest UNESCO report, a significant number of US states and Canadian provinces have conducted mobile learning projects. Apart from that, some US and Canadian universities are also taking initiatives to conduct mobile learning projects [15]. In contrast, even though M-learning concept is gaining popularity in Gulf Cooperative Countries (GCC), initiatives to conduct large scale M-learning projects are rare [15]. Among the few, Qatar University initiated an M-learning project funded by Qatar National Research Fund (QNRF) for professional training in oil and gas sector in collaboration with Canada's Athabasca University [16]. Also, a few years back, UAE (United Arab Emirates) launched a countrywide blended learning project called "smart learning." This project aims at developing an innovative educational setting in schools by furnishing smart classes in all schools providing each student with a notebook and high speed $4 \mathrm{G}$ networks $[17,18]$.

From the above discussion, it is apparent that various studies were conducted in educationally developed countries to adopt M-leaning in practice. It is imperative to study the motivating factors and learners' readiness to accept this new learning technology in higher education institutions from the context of developing countries such as GCC. Hence, the current study aims at overcoming this lagging in the context of higher education institutions in the GCC especially in the Kingdom of Saudi Arabia. The proliferation of mobile devices and wireless technologies does not necessarily mean that M-learning will be adopted in education without any impediment. A number of leaning aspects need to be considered before M-learning can be adopted. Figure 2 depicts different aspects of M-learning such as learners' readiness

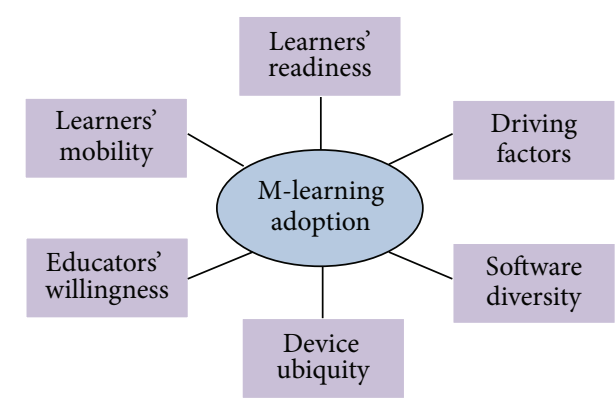

FIGURE 2: M-learning aspects.

to adopt M-learning, driving factors that direct towards learners' acceptance, educators' readiness to use M-learning, learners' mobility, diversity of tools used, and ubiquity of devices. Investigation of learners' perception of M-learning and their readiness to adopt M-learning technology is of utmost importance for successful implementation of this new technology in higher education. Moreover, learners' experience with mobile devices may affect their readiness to adopt M-learning [19].

Therefore, our goal is to investigate learners' readiness to adopt mobile learning in a GCC higher education institution and to identify the impact of learners' previous experience of using mobile devices on adopting this learning technology. A handful of models in the literature propose to examine user's willingness to accept an innovative technology in the globe of information systems. The widely used models among them are the Technology Acceptance Model (TAM) [20], Unified Theory of Acceptance and Use of Technology (UTAUT), and Theory of Planned Behavior (TPB) [21] which work based on behavioral theories. In this study, we plan on using a locally adapted version of UTAUT model to build a research model to investigate learners' readiness of M-learning adoption. To this end, an empirical research is conducted with the participation of undergraduate students of a GCC university. The collected data is then analyzed to examine the used model to make conclusions on learners' readiness to adopt M-learning. The research findings are likely to be helpful for the policy makers in GCC to adopt M-learning, in other words, educational mobile information systems, in higher education institutions. The paper also presents some practical implications of the study results for the acceptance and implementation of this emerging technology in higher education.

The rest of the paper is ordered as follows. Section 2 provides background knowledge and related literature. Research model and hypotheses development are provided in Section 3. Research methodology is presented in Section 4 and discussion of the empirical results and research implications are presented in Sections 5 and 6, respectively. Finally, conclusions are given in Section 7 with some potential future work. 


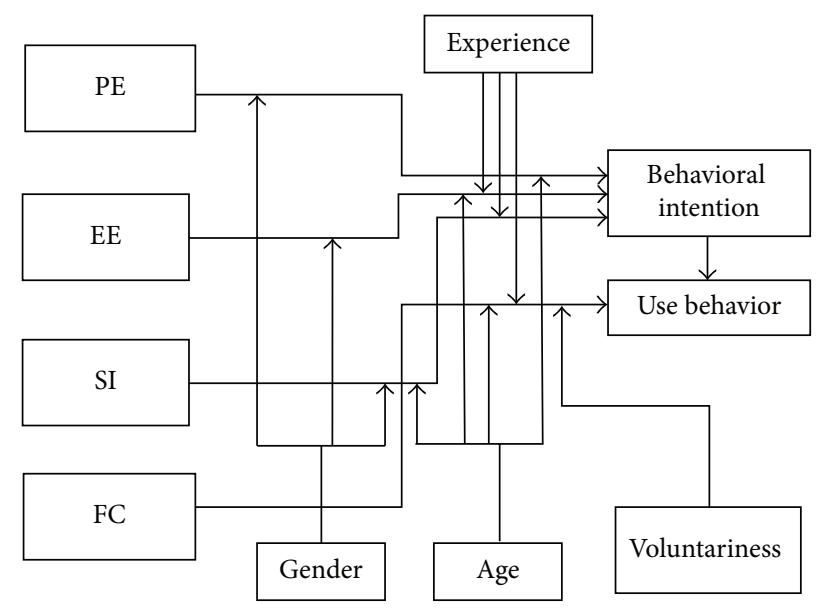

Figure 3: The general UTAUT model.

\section{Theoretical Background and Literature Review}

This section reviews the related studies in the literature that examine the key issues influencing the readiness to adopt M-learning application. As mentioned earlier, a handful of theoretical models propose to investigate the technology adoption. The earliest among them is TAM which works on the adoption of new technology and emphasizes two major variables, namely, usefulness and ease of use perceived by the users [20]. This model also considers few other constructs such as attitude toward use and behavioral intention. In a subsequent study, TAM is modified later on by adding social influence and cognitive instrumental process with the original model [22]. Yet, another model presented in the literature which utilizes TAM as a foundation is called the UTAUT [21]. As given in Figure 3, UTAUT attempts to put together components from various technology acceptance models to come up with a more unified approach. It contains two important constructs, namely, performance expectancy (PE) and effort expectancy (EE), which are referred to as usefulness and ease of use experienced by users in TAM. Additionally, UTAUT contains two other constructs, namely, social influence (SI) and facilitating conditions (FC), which determine user's intent. Furthermore, four other mediating elements, gender, age, experience, and voluntariness of use, are also essential to understand the influence of the major constructs on the user intention of technology adoption. In this paper, we adopted a locally modified version of UTAUT to investigate learners' readiness to adopt M-learning.

A quite a bit of work was done in the literature studying the factors affecting user willingness to accept M-learning technology using UTAUT model. An early effort was done by Ju et al. [23] who conducted a study which involved 245 university students to find out the influence of ease of use on self-efficacy experienced by users. It turned out that the earlier one affects the later one notably which optimistically impacts usefulness and user intention to adopt M-learning. The authors in [24] presented a conceptual framework to analyze the user readiness to use mobile learning technology.
To accomplish that, they extended the UTAUT model and added constructs such as mobility, enjoyment, attainment value, and learning management by user himself. Jairak et al. [25] performed an empirical research to examine the learners' willingness to accept learning methods based on mobile devices in some educational institutions in Thailand. The study found out that all the major constructs have optimistic relationship with learners' intention and significantly affects learners' attitude towards the use of learning technology based on portable devices in higher education. In a contemporary study, Wang et al. [5] managed to find out the major determinants behind the adoption of mobile learning and whether the other two constructs, age and gender, have any notable impact in the adoption of mobile device based learning. The authors modified the original UTAUT model by merging playfulness with learning management. The study results showed that the adapted research model includes all constructs which are major determinants to shape the user readiness to use M-learning in addition to gender and age differences. In a subsequent study, the author in [26] conducted a survey which involved 113 university students and performed data analysis with the same model. The results demonstrated that both types of expectancy played important role in deciding behavioral intention. However, it turned out that self-management in learning does not play notable role in determining the learners' intention. Moreover, gender and age have no intervening influence on user's intention to adopt M-learning. In a relatively novel effort [27], the authors conducted an empirical study in 10 universities in two cities of Pakistan and found out that usefulness, ease of use, and facilitating conditions have notable effect on students' readiness to use M-learning. However, perceived playfulness moderately affects the intention, while social influence has pessimistic relationship to boost students' intention in $\mathrm{M}$ learning adoption. The authors claim that their study findings will be useful for the country's policy-makers, especially educators, in devising mobile learning framework in the perspective of educationally less developed countries.

In the context of GCC, some studies were done in few universities in Oman, UAE, and Bahrain to investigate the driving factors and current status of M-learning adoption in higher education. Sarrab et al. [28] studied the major challenges that are faced by the educators in adopting mobile learning application in higher education institutions. They also considered economic effects where the policy-makers in different organizations plan on adopting M-learning from the scratch. They have carried out three case studies in Oman to discover the impending challenges and benefits of mobile learning adoption in educational institutions. The authors in [29] conducted an empirical study which involved 107 students from the college of IT at University of Bahrain to examine learners' view on using M-learning technology. The research results indicated that there are significant relationships among three major constructs, perceived ease of use, usefulness, and facilitating conditions, which have notable influence on learners' willingness to use this learning method. Al-Emran and Shaalan [30] investigated the attitude of learners and instructors regarding the adoption of learning using portable devices in higher education in United Arab 


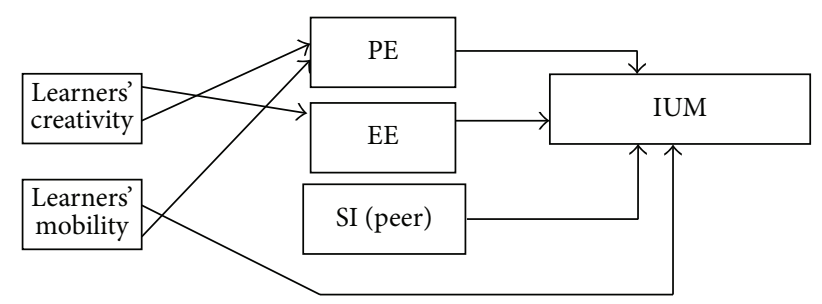

FIgURE 4: Adapted model framework.

Emirates (UAE) and Oman. Total of 383 university students and 84 instructors participated in the study. The research results demonstrated that learners in UAE are more willing to adopt M-learning than those in Oman.

\section{Research Model and Hypotheses Development}

Taking into consideration the specific higher education institution setting in Saudi Arabia, we have modified the original UTAUT model to investigate learners' readiness of M-learning adoption. We have introduced two moderating factors, namely, learners' creativity and mobility in the model (as shown in Figure 4), which might be affecting the major constructs in the model such as performance expectancy (PE), effort expectancy (EE), and social influence (SI). As per social influence, we have taken into consideration peer influence as claimed by Kubilay et al. [31] to be playing a vital role in determining the behavioral intention of the learners. Currently, many of the universities in the KSA do not have any M-learning infrastructure. The universities manage online version of the offered courses through a learning management system called Blackboard. To this end, the current research has undertaken this endeavor to identify the effect of this construct (peer influence) on the readiness of learners in adopting mobile learning. Since the participants of the study are all university students, thus representing the same age range, we eliminated the moderating factor age from the original UTAUT model. Furthermore, we are conducting this study in the perspective of a voluntary practice and hence the effect of voluntariness of use has not been tested. The authors of the model [21] also found out that facilitating conditions do not exhibit considerable influence on learners' intention and hence it was related to use behavior. Consequently, we did not consider facilitating conditions in our adapted model.

As shown in the proposed research model, behavioral intention to use M-learning (IUM) is dependent on three major constructs, PE, EE, and SI, which in turn are dependent on three other moderating factors, namely, learners' creativity, mobility, and gender. Venkatesh et al. [21] describe PE as to what extent learners would find the new technology useful and improving learners' performance. The authors claimed that $\mathrm{PE}$ is the strongest construct that affects $\mathrm{BI}$ the most. A handful of other research outcomes [32-35] also suggested that PE strongly influences BI of the user. Thus, PE can be applied to M-learning research model to determine the efficacy of this new technology to the learners which will affect their readiness to adopt the same as a learning method. PE will also indicate learners' performance increase in terms of productivity [5]. In this study, PE entails both usefulness and learners' performance improvement and thus we anticipate that PE of mobile learning would have optimistic influence on learners' willingness to use M-learning. To this end, we propose to test the following hypothesis.

(H1) Performance expectancy positively influences learners' intention to adopt mobile learning.

Venkatesh et al. [21] describe effort expectancy as to what extent users will find the new technology easy to use. Thus, ease of use becomes a key factor to determine whether a novel technology should be accepted by the users or not [36]. The degree of easiness demonstrated by today's information technology renders a low level of effort expectancy, in other words, high level of ease of use. Research results in the literature advocate that EE can influence BI both positively $[21,33]$ and negatively [37]. The authors in [38] found out that country factor has a moderating effect on the EE which in turn influences BI, while yet another study [39] concluded that users' age can be an important factor that influences EE. Some other studies indicated that the idea of $\mathrm{EE}$ will be a stronger factor influencing user intention for female, especially the elderly ones [21, 40], and users having modest experience with the new technology [40]. Thus, we expect that learners' readiness to accept M-learning will be determined by whether the system is easy to use or not. Hence, the following hypothesis is proposed.

(H2) Effort expectancy significantly influences learners' intention to adopt mobile learning.

As part of the social influence, we considered peer influence which is defined as follows. If a peer learner recommends that a specific system might be useful, a learner thinks that it might be useful for him in reality and hence the learner intends to use it [41]. In particular, peer influence has a superior impact in case of a new system. This fact is also advocated by Agarwal and Prasad [42] who identified that social influence can be described as having two aspects: superior influence and peer influence. Hence, our study takes into account peer influence and investigates its impact on learners' readiness to accept mobile learning.

(H3) Peer influence significantly influences learners' intention to adopt mobile learning.

In the literature, learners' creativity refers to personal innovativeness which is described as to what degree an individual is eager to adopt a new information technology [42]. Individuals with increased level of creativity are more likely to build constructive attitude towards any new information system innovations compared to those with lower level of creativity [43]. A handful of information systems research outcomes demonstrate that individuals' creativity or innovativeness is a vital moderating factor in accepting new technology and has positive influence on users' behavioral intention. Based on this, we anticipated that learners that are creative would be the pioneer in adopting M-learning in their study and thus learners' creativity will have an optimistic relation with $\mathrm{PE}$ and $\mathrm{EE}$ in our modified UTAUT model. Hence, two hypotheses are proposed as follows. 
TABLE 1: Survey questionnaire.

\begin{tabular}{ll}
\hline Constructs & Items used \\
\hline \multirow{3}{*}{ Performance expectancy } & PE_1: M-learning would help me comprehend the course content better. \\
& PE_2: M-learning will enhance my teamwork with my classmates on group work. \\
& PE_3: I think M-learning will facilitate my career development. \\
\hline \multirow{2}{*}{ Effort expectancy } & EE_1: I would say using M-learning is simple. \\
& EE_2: I am eager to make use of an M-learning application if I get some help on how to use it. \\
& EE_3: Revising my course materials will be easier with M-learning. \\
\hline \multirow{2}{*}{ Social influence } & SI_1: My friends will motivate me to use mobile learning. \\
\hline \multirow{2}{*}{ Intention to use } & SI_2: Individuals whom I regard as important would support me to use M-learning. \\
M-learning & IUM_1: I plan to make use of M-learning technologies for my studies. \\
\hline \multirow{3}{*}{ Learners' creativity } & IUM_2: I believe I possess adequate skills to use M-learning applications. \\
& IUM_3: I prefer to use mobile learning over other learning scheme. \\
\hline Learners' mobility & LC_2: I am eager to use new mobile applications. \\
& LC_3: I would take pleasure in using my portable devices for mobile learning application. \\
& LC_4: I am willing to use mobile applications to obtain course materials and work together with my classmates. \\
\hline & LM_1: I can continue studying my courses anywhere and anytime. \\
& LM_2: M-learning will make me use my time economically for learning.
\end{tabular}

(H4) Learners' creativity has a major impact on the relationship of the model and positively influences performance expectancy.

(H5) Learners' creativity has a major impact on the relationship of the model and positively influences effort expectancy.

Mobility means the concept of learning from anywhere and anytime and individuals have the opportunity to utilize their time efficiently to improve performance. Furthermore, mobility becomes an important driving factor in adopting mobile technology for the individuals who want to use their leisure time for learning especially during travel. In the literature $[9,44]$, mobility is explained and deemed vital to acquire real-time information on the move and to be in contact with peer learners and families. Based on this, we expect that mobility would have a positive relation with performance expectancy which in turn will persuade learners' willingness to use mobile learning. Hence, the following two hypotheses are proposed.

(H6) Mobility shows a major impact on the relationship of the model and positively influences performance expectancy.

(H7) Mobility positively influences learners' intention to adopt mobile learning.

\section{Research Methodology}

4.1. Research Design. Our study makes use of structural equation modeling (SEM) to evaluate the proposed model by assessing the relationships among four major constructs of the model, PE, EE, SI, and learners' intention to use M-learning (IUM), and the effect of moderating variables or constructs such as learners' creativity (LC) and learners' mobility (LM) (as outlined in Figure 4) on the major constructs. The study was initiated through a survey questionnaire consisting of 21 items evaluating all six constructs based on a five-point Likert scale. It ranges from strongly disagree (1) to strongly agree (5). PE is assessed using three items which primarily describe the improvement in performance and productivity. EE is assessed using three items and focuses on the degree of easiness in using M-learning technology. SI is measured using two items focusing on peer influences. LC is assessed using four items which deal with learners' creativity and eagerness to try out novel technologies. LM consists of two items and leverages the concept of being on the move and keeping learning. IUM is assessed using three items and primarily concentrates on learners' intention or readiness to use mobile learning in higher education level. Table 1 outlines the questionnaire that was delivered for conducting the survey.

Since the focus of our study is to evaluate the inclination of learners to adopt mobile learning in higher education institutions in the GCC, we made university students as our target group for the survey. The participants are the undergraduate students of a GCC university. The students are from different years of the program in the College of Computers and Information Technology and are asked to participate in the survey in their classes. A concise introduction to the study goals and a brief explanation of M-learning were presented by the instructor ahead of the survey. A grand total of 85 questionnaires are distributed for responses. One questionnaire is removed due to being incomplete and thus we consider sample data from 84 participants. The participants are having an age range of 18 to 25 years.

4.2. Data Analysis and Results. We have performed data analysis in two phases. The first phase includes the appraisal of the measurement model to scrutinize whether the model is a good fit with the collected data or not. The second phase deals with hypothesis testing to verify the supported hypotheses among the proposed ones. The statistical analysis of survey data is completed with WarpPLS 5.0 tool.

We have assessed the measurement model with respect to item loading, measurement reliability, discriminant validity, and convergent validity. The following principles as proposed 
TABLE 2: Descriptive statistics for the measurement model.

\begin{tabular}{lccc}
\hline Constructs and items & Mean & $\begin{array}{c}\text { Standard } \\
\text { deviation }\end{array}$ & $\begin{array}{c}\text { Item } \\
\text { loading }\end{array}$ \\
\hline PE & & & \\
PE_1 & 3.678 & 1.214 & 0.790 \\
PE_2 & 3.833 & 1.160 & 0.810 \\
PE_3 & 4.226 & 0.986 & 0.843 \\
EE & & & \\
EE_1 & 4.345 & 1.227 & 0.860 \\
EE_2 & 4.178 & 1.224 & 0.855 \\
EE_3 & 3.976 & 1.053 & 0.740 \\
SI & & & \\
SI_1 & 3.869 & 1.130 & 0.841 \\
SI_2 & 3.690 & 1.170 & 0.841 \\
IUM & & & \\
IUM_1 & 4.071 & 1.230 & 0.831 \\
IUM_2 & 3.964 & 1.197 & 0.626 \\
IUM_3 & 3.916 & 1.078 & 0.835 \\
Learners' creativity & & & \\
LC_1 & 4.0 & 1.232 & 0.845 \\
LC_2 & 4.142 & 1.132 & 0.796 \\
LC_3 & 4.0 & 1.242 & 0.790 \\
LC_4 & 4.059 & 1.186 & 0.828 \\
Learners' mobility & & & 0.881 \\
LM_1 & 4.261 & 1.142 & \\
LM_2 & 4.071 & 1.170 & \\
\hline
\end{tabular}

by the authors in [45] are used to assess the model: (a) an item is regarded to be reliable if item loading is greater than 0.70 ; an even more relaxed version sets this threshold at 0.6 [46]; (b) the reliability of measure is inspected by using Cronbach's alpha and composite reliability and both of them should be greater than 0.7 ; (c) convergent validity is evaluated by means of average variance extracted (AVE) which is expected to be greater than 0.5 ; (d) the discriminant validity among the proposed variables is assessed by means of the square root of each AVE. This needs to be more than the correlation between any pair of constructs [45]. Tables 2, 3, and 4 show the evaluation results of the model which demonstrate that all the values are from acceptable ranges. Overall, the assessment results show that the measurement model reveals sufficient level of reliability and discriminant and convergent validity.

4.3. Hypothesis Testing and Model Validation. For hypotheses testing, a structural model is used to calculate path coefficients and the variances among the constructs of the model. In particular, variances in the dependent variables or constructs are expounded to evaluate the ability of the model. On the other hand, we evaluate the statistical significance of the proposed hypotheses by using the path coefficients. Figure 5 demonstrates the results of the measurement model including path coefficients and the variances. The values on
TABLE 3: Measuring model reliability and convergent validity.

\begin{tabular}{lccc}
\hline Construct & AVE & $\begin{array}{c}\text { Composite } \\
\text { reliability }\end{array}$ & $\begin{array}{c}\text { Cronbach's } \\
\text { alpha }\end{array}$ \\
\hline PE & 0.663 & 0.855 & 0.746 \\
EE & 0.673 & 0.860 & 0.755 \\
SI & 0.708 & 0.829 & 0.587 \\
IUM & 0.593 & 0.811 & 0.649 \\
LC & 0.664 & 0.888 & 0.831 \\
LM & 0.777 & 0.875 & 0.713 \\
\hline
\end{tabular}

TABLE 4: Discriminant validity and correlation measures of the model.

\begin{tabular}{lcccccc}
\hline Construct & PE & EE & SI & IUM & LC & LM \\
\hline PE & 0.815 & & & & & \\
EE & 0.660 & 0.820 & & & & \\
SI & 0.543 & 0.511 & 0.841 & & & \\
IUM & 0.605 & 0.739 & 0.614 & 0.770 & & \\
LC & 0.635 & 0.782 & 0.611 & 0.742 & 0.815 & \\
LM & 0.631 & 0.786 & 0.453 & 0.647 & 0.720 & 0.881 \\
\hline
\end{tabular}

the edges of the graph represent the path coefficients and variances are shown in terms of percentages.

As expected, learners' creativity shows significant influence on performance expectancy which is confirmed by the path coefficient between these two constructs $(0.40$, $p<0.05)$. Hence, the study indicates that hypothesis 4 is supported. In addition, learners' creativity shows a significant influence on effort expectancy as reported by the path coefficient $(0.79, p<0.05)$. The results thus suggest that an effective policy could be to encourage learners with high creativity in the beginning of M-learning adoption since it exhibits a positive influence on effort expectancy. As agreement with hypotheses (H6) and (H7), learners' mobility is proven to be strongly effective on both performance expectancy and learners intention to use mobile learning. This is supported by the study results where the path coefficients on the link between learners' mobility and other two constructs are shown to be $0.38, p<0.05$, and $0.11, p<0.05$, respectively.

Furthermore, the study results show that all the major constructs such as performance and effort expectancies and social influence have strong effect on learners' behavioral intent to adopt M-learning. This fact is verified by the obtained path coefficients between these major constructs and learners' willingness to make use of M-learning which are $0.08,0.45$, and 0.30 , respectively, with $p<0.05$ in call cases. To further investigate the construct that affects the learners' intention of M-learning usage the most, we figured out that the total effect of effort expectancy (0.45) is much higher than that of any other construct. Also, learners' mobility shows a significant effect on the learners' intention to use M-learning and it indicates the fact that learners' mobility could be a significant predictor of learners' readiness of M-learning usage as a medium of study. This result indicates learners' preference of learning anywhere and anytime. Table 5 summarizes the effect of each construct on 


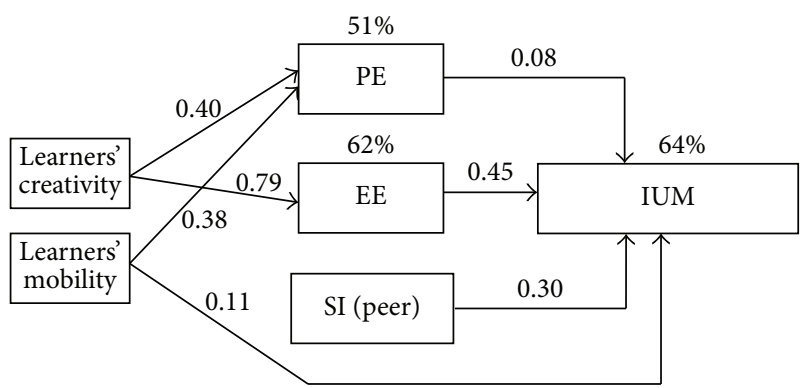

$\longrightarrow$ Hypothesis is supported

Figure 5: Results of the hypotheses test. All the path coefficients are significant at $p<0.05$.

TABLE 5: Coefficient values of the hypotheses.

\begin{tabular}{lcccc}
\hline Hypothesis & Path & Coefficient & $p$ value & Supported \\
\hline (H1) & (PE, IUM) & 0.08 & $<0.001$ & Yes \\
$(\mathrm{H} 2)$ & (EE, IUM) & 0.45 & $<0.001$ & Yes \\
$(\mathrm{H} 3)$ & $($ SI, IUM) & 0.30 & $<0.001$ & Yes \\
$(\mathrm{H} 4)$ & $(\mathrm{LC}, \mathrm{PE})$ & 0.40 & $<0.001$ & Yes \\
$(\mathrm{H} 5)$ & $(\mathrm{LC}, \mathrm{EE})$ & 0.79 & $<0.001$ & Yes \\
$(\mathrm{H} 6)$ & $(\mathrm{LM}, \mathrm{PE})$ & 0.38 & $<0.001$ & Yes \\
$(\mathrm{H} 7)$ & $(\mathrm{LM}, \mathrm{IUM})$ & 0.11 & $<0.001$ & Yes \\
\hline
\end{tabular}

the corresponding dependent constructs which lead to the conclusion whether a proposed hypothesis is supported or not. It is important to note that learners' mobility accounts for $51 \%$ of the variance of performance expectancy. In addition, learners' creativity accounts for $62 \%$ of the variance of effort expectancy. Overall, our M-learning research model explains $64 \%$ of the variance in learners' willingness of M-learning usage.

\section{Discussion of Research Results}

The study results help us to empirically investigate the university students' perception and readiness towards the utilization of mobile learning in higher education studies. This is also apparent from the results where a number of motivating factors are proven to be the key to the successful adoption of mobile learning in the current context. The significant influence of performance and effort expectancies confirm the validity of using an adapted UTAUT model to investigate the learners' readiness to use M-learning which is indicated by their behavioral intention to use the same. Learners with an increased level of performance expectancy think that the application of a learning system with mobile devices will be advantageous for them to improve the productivity of their studies by utilizing time that is spent in an unproductive way during travel and commuting. This leads to the fact that learners with relatively high performance expectancy will tend to accept M-learning more readily as compared to the group with lower performance expectancy. To this end, it is imperative for M-learning designers to ensure that M-learning contents should carry a prolonged benefit in learners' career development in the future. Furthermore, high impact of effort expectancy indicates learners' view on mobile learning to be user-friendly and they do not require rigorous instructions to become comfortable with the new system. Again, this directs to the fact that M-learning designers need to furnish higher education programs with user-friendly M-learning tools and applications. In our study, we have considered social influence from the perspective of peer influence. Results of the study demonstrate that peers' acceptance and their thoughts about M-learning will influence learners' perception about this innovative technology and will encourage them to use it. However, a relatively lower path coefficient (as shown in Table 5) reveals the fact that social influence in the current context is shown to be a less significant determinant of learners' M-learning adoption among the other constructs.

As expected, based on the prior studies, learners' creativity, also named as personal innovativeness, in our model has significant impact on effort expectancy due to the fact that creative learners will find the new system easy to use which in turn will influence them to use M-learning. This implies that learners with high creativity will find themselves confident in using M-learning applications and will more likely be willing to adopt them as learning methods. In contrast to the previous studies, the current study results show that learners' creativity does not have significant impact on performance expectancy. This can be attributed to the fact that innovative learners in the chosen higher education institution having an easy to use perception about M-learning deem this expertise an insignificant predictor of performance expectancy. The other moderating variable, learners' mobility, shows a noteworthy effect on PE and willingness to use mobile learning. In fact, the total effect of learners' mobility on intention of mobile learning usage is the highest among all other constructs. This is due to the fact that the participants of the study consider that the flexibility of learning by using mobile devices and being anywhere anytime will boost their interest in pursuing higher studies. This salient feature of mobile learning technology and our research finding will strengthen learners' intention of adopting this technology in the higher education institutions.

\section{Research Implications}

A number of practical and theoretical implications can be made from our research findings which will add to the success story of next generation innovative mobile information systems. This study methodically demonstrates learners' attitude and readiness of using of mobile learning in higher education by integrating our research findings and mobile information systems from the perspective of education literature. As such, we conclude that the usage of locally modified UTAUT model to validate the application of Mlearning is justified. As UTAUT was originally formulated as a technology acceptance model to establish user intent to use it in an information system, additional consideration is needed when the model is applied to an educational environment in a mobile information system context. For example, the 
proposed research model has included learners' mobility and creativity to mediate the influence of three key constructs on the learners' intention of mobile learning usage which in turn gives birth to a solid acceptance model in investigating learners' readiness to accept educational mobile information systems. The empirical results advocate the hypotheses that both learners' mobility and creativity have positive impact on performance and effort expectancies, respectively, which are stronger determinants of learners' readiness to use Mlearning as an educational mobile information system. Even though the social atmosphere is vital for young learners, research findings demonstrate that it has less significance in determining learners' behavioral intention towards using mobile information systems.

The future innovative mobile systems are mostly going to focus on attracting user attention to use the mobile devices in academics and in businesses as well. The diverse capabilities of portable devices will dramatically enhance next generation mobile information systems. As such, the dynamic phase of mobile technology will take M-learning to a new height where both academics and industries will reap benefits in terms of providing diverse learning experiences to the innovative learners. Hence, we state that our M-learning research findings will offer helpful insights for policy-makers and researchers to better understand learners' perception and attitude towards M-learning and to assess the prospect of applying such mobile technologies in the context of higher education institutions in GCC countries and particularly Saudi Arabia. Additionally, our current research will open the door of future research to fully analyze the successful M-learning requirements and to design a comprehensive M-learning system to add to the success stories of next generation innovative mobile information systems.

\section{Conclusions and Future Research}

The goal of our study is to investigate learners' readiness to adopt mobile learning in higher education institution in the context of GCC countries and especially Saudi Arabia. To this end, the study reviews the prospects and challenges of adopting this learning technology in higher education level from the GCC as well as global perspective. A locally modified UTAUT model is used to assess learners' readiness to use M-learning technology in higher education. As such, two additional constructs, namely, learners' creativity and mobility, are added to the research model. An empirical study is conducted among undergraduate students to validate the proposed research model and to examine the impacts of various variables on learners' readiness to adopt M-learning. The empirical results show that learners' attitude towards using this new technology is encouraging. The learners in higher education level are ready to adopt mobile learning in their studies and prefer the flexibility of this approach over traditional class room based learning. The results also show that performance expectancy, in other words, usefulness of M-learning, is the most significant determining construct of learners' readiness to use this new technology followed by effort expectancy and peer influence. Overall, the research findings will help researchers and policy-makers come up with design decisions on how to implement such technologies in learning context in higher education institutions in Gulf region and especially in Saudi Arabia.

The current study shows the results from empirical research and hence some limitations need to be discussed which can be addressed in future research. The participants of the study are from only one university and from the same discipline. Hence, the sample data does not necessarily represent all the students in the university from different disciplines. In future, we plan to collect data from participants with different educational background and from different institutions in the GCC to investigate if their demographic data have substantial influence on the perspective of the learners on M-learning technology. Moreover, instructors have a significant role to motivate students for the adoption of this new technology in higher education. Further investigation should be done to identify the instructors' perception of mobile learning and the challenges that they anticipate in adopting this novel learning method in higher education institutions in Gulf region.

\section{Competing Interests}

The authors declare that they have no competing interests.

\section{Acknowledgments}

The authors extend their appreciation to the Deanship of Scientific Research at King Saud University, Riyadh, Saudi Arabia, for funding this work through the research group Project no. RG-1436-016.

\section{References}

[1] C. Karagiannidis, A. Koumpis, and G. Lekakos, "m-Learning and $\mathrm{m}$-commerce in pervasiveenvironments," The Electronic Journal for Emerging Tools and Applications, 2009.

[2] H. Peng, Y.-J. Su, C. Chou, and C.-C. Tsai, "Ubiquitous knowledge construction: mobile learning re-defined and a conceptual framework," Innovations in Education and Teaching International, vol. 46, no. 2, pp. 171-183, 2009.

[3] Statista, The Statistical Portal, November 2015, http://www .statista.com/statistics/470018/mobile-phone-user-penetrationworldwide/.

[4] Ministry of Communication and Information Technology, ICT Indicators in KSA, Ministry of Communication and Information Technology, Riyadh, Saudi Arabia, 2015, http://www .mcit.gov.sa/En/aboutmcit/sectordevelopment/pages/sectorindices.aspx.

[5] Y.-S. Wang, M.-C. Wu, and H.-Y. Wang, "Investigating the determinants and age and gender differences in the acceptance of mobile learning," British Journal of Educational Technology, vol. 40, no. 1, pp. 92-118, 2009.

[6] M. S. Hossain and A. El Saddik, "A biologically inspired multimedia content repurposing system in heterogeneous environments," Multimedia Systems, vol. 14, no. 3, pp. 135-143, 2008.

[7] M. S. Hossain, A. Alamri, and A. E. Saddik, "A biologically inspired framework for multimedia service management in a ubiquitous environment," Concurrency Computation: Practice and Experience, vol. 21, no. 11, pp. 1450-1466, 2009. 
[8] M. S. Hossain and A. El-Saddik, "Scalability analysis for personalized multimedia repurposing system," in Proceedings of the IEEE Instrumentation and Measurement Technology Conference (IEEE-IMTC '06), Sorrento, Italy, April 2006.

[9] A. El-Saddik and M. S. Hossain, "Multimedia content repurposing," in Encyclopedia of Multimedia, Springer US, 2006.

[10] M. S. Hossain, S. K. A. Hossain, A. Alamri, and M. A. Hossain, "Ant-based service selection framework for a smart home monitoring environment," Multimedia Tools and Applications, vol. 67, no. 2, pp. 433-453, 2013.

[11] M. S. Hossain, "QoS-based service composition for distributed video surveillance," Multimedia Tools and Applications, vol. 73, no. 1, pp. 169-188, 2014.

[12] M. Shorfuzzaman, A. Alelaiwi, M. Masud, M. Hassan, and M. S. Hossain, "Usability of a cloud-based collaborative learning framework to improve learners' experience," Elsevier Computers in Human Behavior B, vol. 51, pp. 967-976, 2015.

[13] M. Sharples, I. Sánchez, M. Milrad, and G. Vavoula, "Mobile learning: small devices, big issues," in Technology Enhanced Learning: Principles and Products, Springer, Berlin, Germany, 2009.

[14] MoLeNET, Mobile Learning in Practice, November 2015, http://www.molenet.org.uk/mobilearinprac.html.

[15] UNESCO Mobile Learning Publications, November 2015, http://www.unesco.org/new/en/unesco/themes/icts/m4ed/mobile-learning-resources/unescomobilelearningseries/.

[16] “QU M-Learning Project for Oil and Gas Sector," http://www .gulf-times.com/qatar/178/details/375837/qu-developing-mlearning-project-for-oil-26-gas-sector.

[17] VllOonYrLIV, "UAE launches \#72m 'smart learning' initiative," http://www.arabianbusiness.com/uae-launches-272m-smartlearning-initiative-453466.html\#.

[18] A. Alelaiwi, A. Alghamdi, M. Shorfuzzaman, M. Rawashdeh, M. S. Hossain, and G. Muhammad, "Enhanced engineering education using smart class environment," Computers in Human Behavior, vol. 51, pp. 852-856, 2015.

[19] J. Cheon, S. Lee, S. M. Crooks, and J. Song, "An investigation of mobile learning readiness in higher education based on the theory of planned behavior," Computers and Education, vol. 59, no. 3, pp. 1054-1064, 2012.

[20] F. D. Davis, "Perceived usefulness, perceived ease of use, and user acceptance of information technology," MIS Quarterly, vol. 13, no. 3, pp. 319-339, 1989.

[21] V. Venkatesh, M. G. Morris, G. B. Davis, and F. D. Davis, "User acceptance of information technology: toward a unified view," MIS Quarterly: Management Information Systems, vol. 27, no. 3, pp. 425-478, 2003.

[22] V. Venkatesh and F. D. Davis, "A theoretical extension of the technology acceptance model: four longitudinal field studies," Management Science, vol. 46, no. 2, pp. 186-204, 2000.

[23] T. L. Ju, W. Sriprapaipong, and D. N. Minh, "On the success factors of mobile learning," in Proceedings of the 5th International Conference on ICT and Higher Education, Bangkok, Thailand, 2007.

[24] Y. Liu, "An adoption model for mobile learning," in Proceeding of the IADIS International Conference on e-Commerce, Amsterdam, Netherlands, July 2008.

[25] K. Jairak, P. Praneetpolgrang, and K. Mekhabunchakij, "An acceptance of mobile learning for higher education students in Thailand," in Proceedings of the 6th International Conference on E-Learning for Knowledge-Based Society, December 2009.
[26] J. N. Lowenthal, "Using mobile learning: determinates impacting behavioral intention," The American Journal of Distance Education, vol. 24, no. 4, pp. 195-206, 2010.

[27] S. Iqbal and I. A. Qureshi, "M-learning adoption: a perspective from a developing country," The International Review of Research in Open and Distance Learning, vol. 13, no. 3, pp. 147$164,2012$.

[28] M. Sarrab, H. Al-Shihi, and O. H. Rehman, "Exploring major challenges and benefits of M-learning adoption," British Journal of Applied Science \& Technology, vol. 3, no. 4, pp. 826-839, 2013.

[29] M. F. Al-Ani, S. M. Hameed, and L. Faisal, "Students' perspectives in adopting mobile learning at university of Bahrain," in Proceedings of the 4th International Conference on e-Learning "Best Practices in Management, Design and Development of $e$ Courses: Standards of Excellence and Creativity”, pp. 86-89, Manama, Bahrain, May 2013.

[30] M. Al-Emran and K. Shaalan, "Attitudes towards the use of mobile learning: a case study from the gulf region," International Journal of Interactive Mobile Technologies, vol. 9, no. 3, pp. 75-78, 2015.

[31] M. Kubilay, B. Nuri, and E. Gülcan, "Exploring major determinants of mobile learning adoption," in Proceedings of the Technology Management for Emerging Technologies (PICMET '12), pp. 1415-1423, Vancouver, Canada, July-August 2012.

[32] T. Casey and E. Wilson-Evered, "Predicting uptake of technology innovations in online family dispute resolution services: an application and extension of the UTAUT," Computers in Human Behavior, vol. 28, no. 6, pp. 2034-2045, 2012.

[33] B. Gupta, S. Dasgupta, and A. Gupta, "Adoption of ICT in a government organization in a developing country: an empirical study," The Journal of Strategic Information Systems, vol. 17, no. 2, pp. 140-154, 2008.

[34] Z. Zhang and R. F. Kenny, "Learning in an online distance education course: experiences of three international students," The International Review of Research in Open and Distance Learning, vol. 11, no. 1, pp. 17-36, 2010.

[35] Y. K. Dwivedi, N. P. Rana, H. Chen, and M. D. Williams, "A meta-analysis of the unified theory of acceptance and use of technology (UTAUT)," in Governance and Sustainability in Information Systems- Managing the Transfer and Diffusion of IT, vol. 366, pp. 155-170, Springer, Berlin, Germany, 2011.

[36] Y. Wu, Y. Tao, and P. Yang, "The use of unified theory of acceptance and use of technology to confer the behavioral model of 3G mobile telecommunication users," Journal of Statistics \& Management Systems, vol. 11, no. 5, pp. 919-949, 2008.

[37] A. Gruzd, K. Staves, and A. Wilk, "Connected scholars: examining the role of social media in research practices of faculty using the UTAUT model," Computers in Human Behavior, vol. 28, no. 6, pp. 2340-2350, 2012.

[38] I. Im, S. Hong, and M. S. Kang, "An international comparison of technologyadoption: testing the UTAUT model," Information \& Management, vol. 48, no. 1, pp. 1-8, 2011.

[39] Y.-S. Wang and Y.-W. Shih, "Why do people use information kiosks? A validation of the unified theory of acceptance and use of technology," Government Information Quarterly, vol. 26, no. 1, pp. 158-165, 2009.

[40] V. Venkatesh, M. G. Morris, and P. L. Ackerman, "A longitudinal field investigation of gender differences in individual technology adoption decision-making processes," Organizational Behavior and Human Decision Processes, vol. 83, no. 1, pp. 33-60, 2000 . 
[41] V. Venkatesh and M. G. Morris, "Why don't men ever stop to ask for directions? Gender, social influence, and their role in technology acceptance and usage behavior," MIS Quarterly, vol. 24, no. 1, pp. 115-136, 2000.

[42] R. Agarwal and J. Prasad, "A conceptual and operational definition of personal innovativeness in the domain of information technology," Information Systems Research, vol. 9, no. 2, pp. 204215, 1998.

[43] J. Lu, J. E. Yao, and C.-S. Yu, "Personal innovativeness, social influences and adoption of wireless internet services via mobile technology," Journal of Strategic Information Systems, vol. 14, no. 3, pp. 245-268, 2005.

[44] L. Kleinrock, "Nomadicity: anytime, anywhere in a disconnected world," Mobile Networks and Applications, vol. 1, no. 4, pp. 351-357, 1996.

[45] C. Fornell and D. F. Larcker, "Evaluating structural equation models with unobservable variables and measurement error," Journal of Marketing Research, vol. 18, no. 1, pp. 39-50, 1981.

[46] J. C. Nunnally and I. H. Bernstein, Psychometric Theory, McGraw-Hill, New York, NY, USA, 1994. 

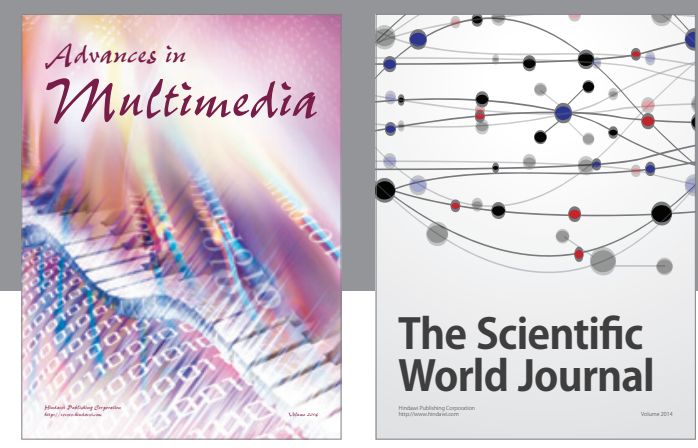

The Scientific World Journal
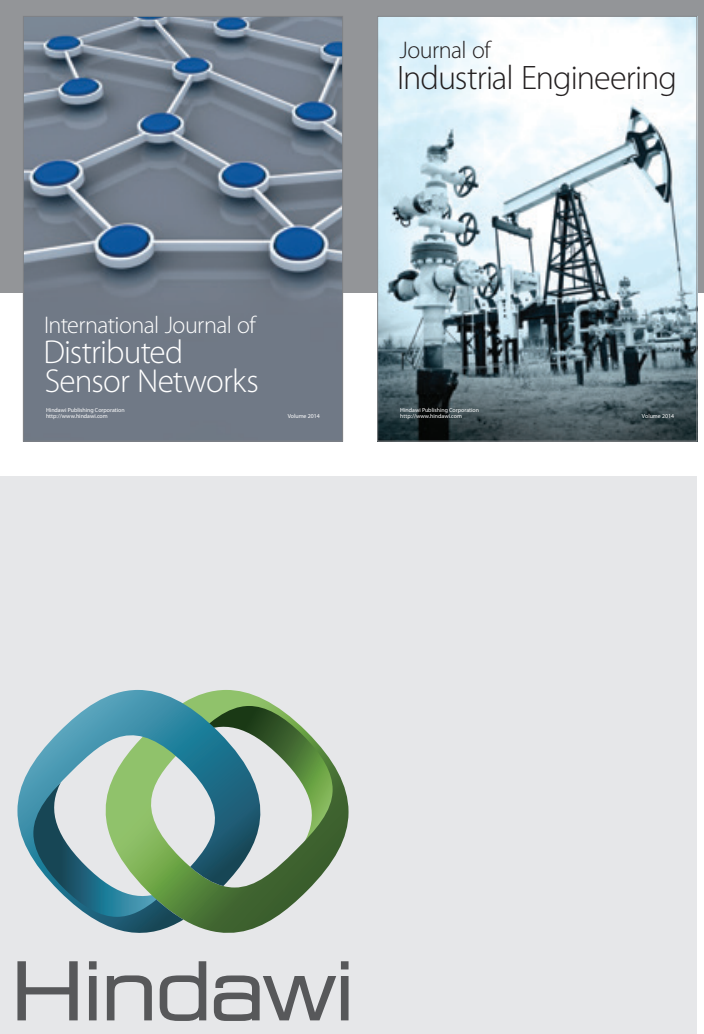

Submit your manuscripts at

http://www.hindawi.com

\section{Computer Networks} and Communications
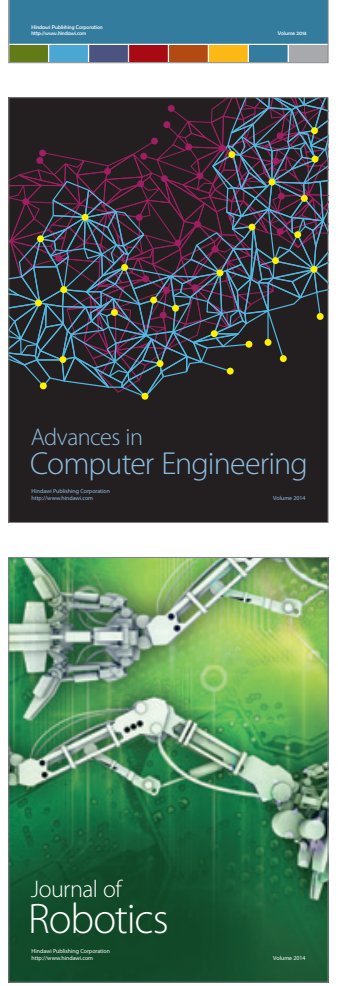
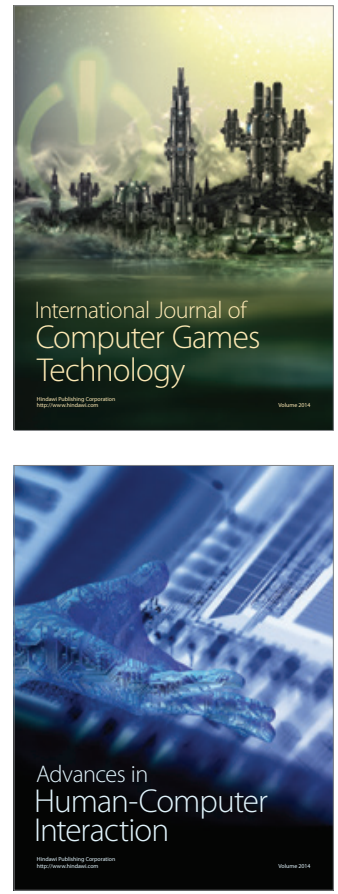
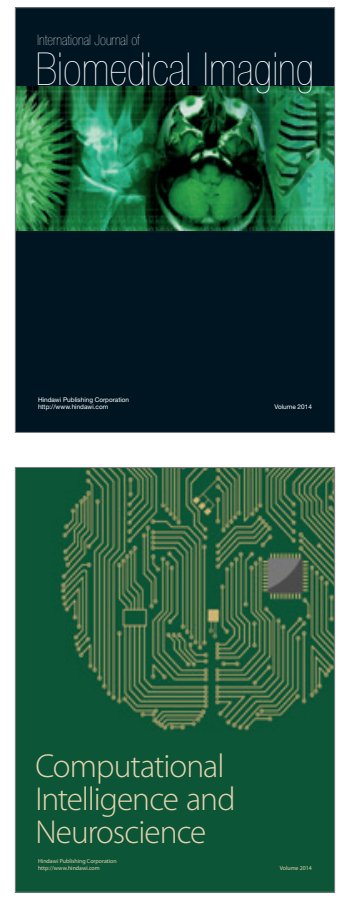
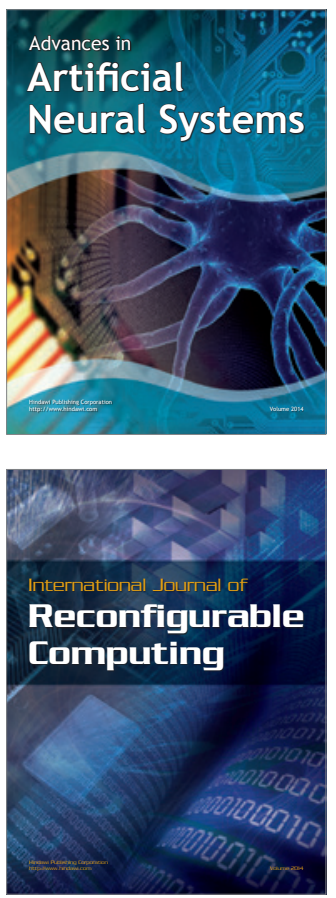
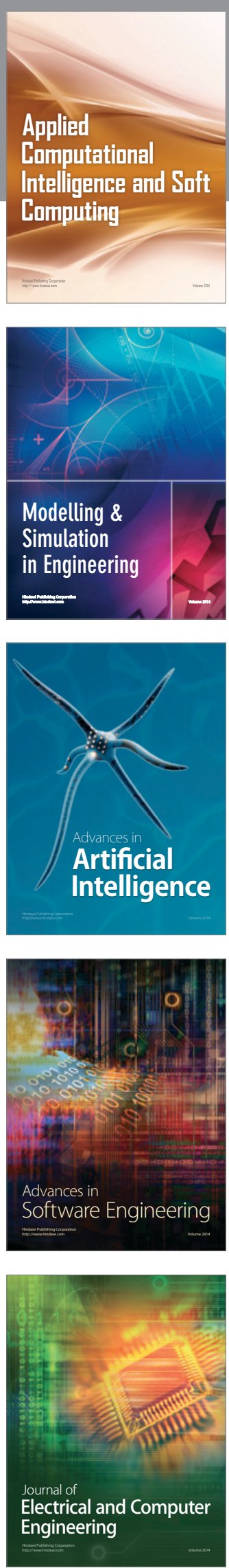